\title{
Single-port laparoscopic adrenalectomy for a right-sided aldosterone-producing adenoma: a case report
}

\author{
Akira Sasaki*, Shigeaki Baba, Toru Obuchi, Akira Umemura, Masaru Mizuno and Go Wakabayashi
}

\begin{abstract}
Introduction: Single-port laparoscopic adrenalectomy is one of the most interesting surgical advances. Here, we evaluate the safety and feasibility of single-port laparoscopic adrenalectomy as treatment for a right-sided aldosterone-producing adenoma.

Case presentation: A 39-year-old Japanese woman presented with hypertension and hypokalemia. Abdominal computed tomography and an endocrinological workup revealed a $19 \mathrm{~mm}$ right adrenal tumor with primary aldosteronism. Our patient was informed of the details of the surgical procedure and our efforts to reduce the number of incisions needed - ideally, to a single incision - when removing her adrenal gland. A single-port laparoscopic adrenalectomy was attempted. A multichannel port was inserted through a $2.5 \mathrm{~cm}$ umbilical incision. A $5 \mathrm{~mm}$ flexible laparoscope, articulating laparoscopic dissector and tissue sealing device were the primary tools used in the operation. The right liver lobe was evaluated using a percutaneous instrument, providing good visualization of the operative field surrounding her right adrenal gland. The single-port laparoscopic adrenalectomy was successfully completed without any intraoperative complications. The operating time was 76 minutes, and her blood loss was $5 \mathrm{~mL}$. Oral intake was resumed on the first postoperative day, and the length of her hospital stay was three days. Her postoperative course was uneventful with no morbidity within one month of follow-up, and our patient had excellent cosmetic results.
\end{abstract}

Conclusions: Single-port laparoscopic adrenalectomy is a safe and feasible procedure for patients with a rightsided adrenal tumor when performed by a surgeon experienced in laparoscopic and adrenal surgery. However, more surgical experience using this technique is required to confirm our initial impressions.

\section{Introduction}

Since Gagner et al. [1] reported the first multiport laparoscopic adrenalectomy (MPLA) in 1992, minimally invasive procedures have become the standard methods used for most patients with benign adrenal tumors [2-5]. Recently, a trial of single-port surgery (SPS) was started because SPS has the potential to provide patients with improved cosmetic outcomes, less postoperative wound pain and fewer wound complications; as such, it satisfies a growing demand for less invasive surgical procedures [6-8]. Now, interest in SPS has greatly increased worldwide. Since January 2010, we have performed single-port laparoscopic adrenalectomies (SPLAs) for 10 patients

\footnotetext{
* Correspondence: sakira@iwate-med.ac.jp

Department of Surgery, Iwate Medical University School of Medicine, 19-1 Uchimaru, Morioka 0200-8505, Japan
}

with benign adrenal tumors. However, the technical challenges of right-sided SPLA have prevented its widespread use. The aim of this report was to evaluate the safety and feasibility of SPLA for the treatment of a right-sided aldosterone-producing adenoma.

\section{Case presentation}

A 39-year-old Japanese woman (body mass index of $18 \mathrm{~kg} / \mathrm{m}^{2}$ ) with a past medical history of hypertension was referred to our hospital because of hypertension and hypokalemia. She had a history of a Cesarean section at 30 years old. A $19 \mathrm{~mm}$ right adrenal tumor was found on abdominal computed tomography (Figure 1). Bilateral adrenal vein catheterization was performed to obtain plasma samples from both her adrenal veins and infrarenal inferior vena cava. The basal aldosterone levels in

\section{Biomed Central}




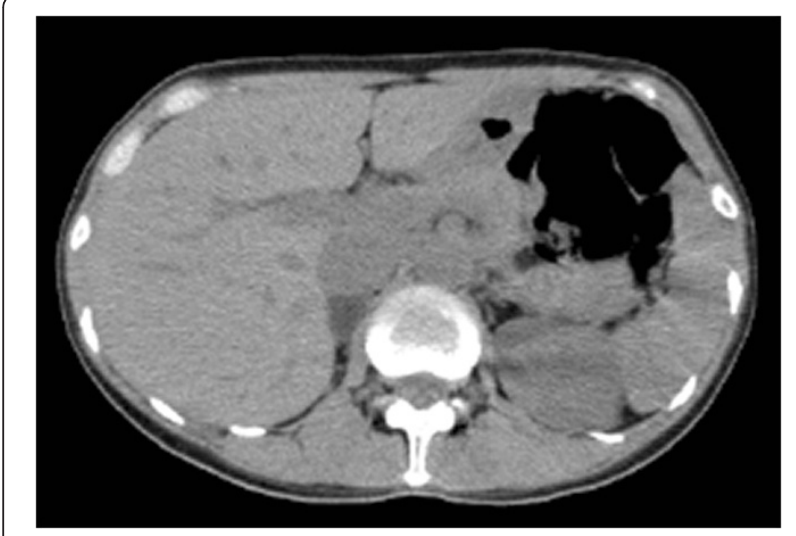

Figure 1 Abdominal computed tomography showing a $19 \mathrm{~mm}$ right adrenal tumor.

her right and left adrenal vein were found to be $51,900 \mathrm{pg} / \mathrm{mL}$ and $1,200 \mathrm{pg} / \mathrm{mL}$, respectively. Thirty minutes after stimulation with adrenocorticotropic hormone, these levels rose to $113,000 \mathrm{pg} / \mathrm{mL}$ and $1,5100 \mathrm{pg} / \mathrm{mL}$, respectively. The aldosterone-to-cortisol ratio was 340 times higher in her right adrenal vein than in her left adrenal vein. These findings demonstrated that her right adrenal gland was the source of excess aldosterone secretion.

Our patient was informed about the details of the surgical procedure and our efforts to reduce the number of incisions needed - ideally, to a single incision - when removing her adrenal gland. A SPLA was attempted.

Our patient was placed in the left semilateral position. A $2.5 \mathrm{~cm}$ incision was made on the umbilicus, and a multichannel port (SILS ${ }^{\mathrm{TM}}$ port; Covidien, Mansfield, MA, USA) was inserted (Figure 2). The pneumoperitoneal pressure was maintained at $10 \mathrm{mmHg}$. Three $5 \mathrm{~mm}$ cannulas were inserted through the SILS ${ }^{\mathrm{TM}}$ port. The

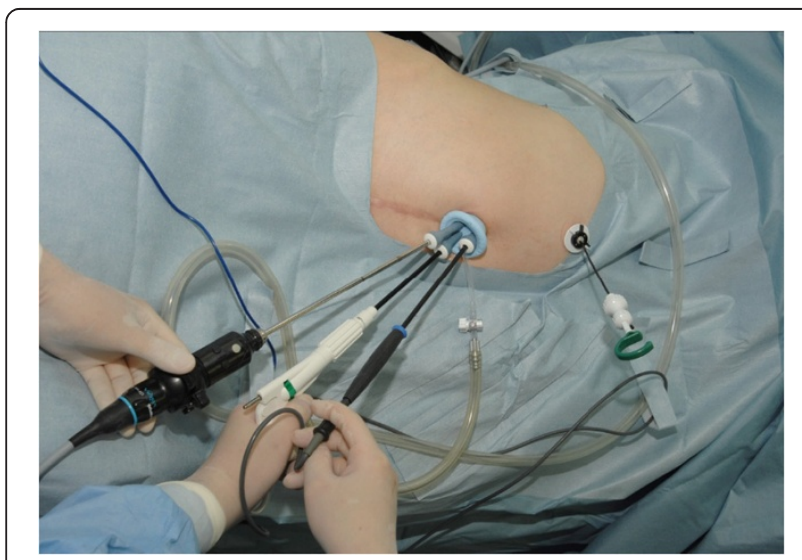

Figure 2 Port placement for right single-port laparoscopic adrenalectomy. The SILS $S^{\text {TM }}$ port was placed through a $2.5 \mathrm{~cm}$ umbilical skin incision. primary tools used in the operation were a $5 \mathrm{~mm}$ flexible laparoscope (Olympus Medical Systems, Tokyo, Japan), a roticulated laparoscopic dissector (Covidien) and a tissue sealing device $\left(\mathrm{ENSEAL}^{\circledR}\right.$; Ethicon, Cincinnati, $\mathrm{OH}$, USA). Her right liver lobe was evaluated using a percutaneous instrument (MiniLap; Stryker, Kalamazoo, MI, USA), providing good visualization of the operative field surrounding the right adrenal gland (Figure 3). The overall procedure was similar to the procedure performed in a conventional laparoscopic anterior adrenalectomy using a four-port technique. Only her right central adrenal vein was clipped and the small adrenal vessels were divided using an ENSEAL ${ }^{\circledR}$. Her adrenal gland was extracted via a retrieval bag by removing one $5 \mathrm{~mm}$ cannula and upsizing to a $12 \mathrm{~mm}$ cannula. The skin was closed with absorbable sutures. No drains were inserted.

SPLA was successfully completed without the need for any skin incisions or additional ports. The operating time was 76 minutes, and her blood loss was $5 \mathrm{~mL}$. Oral intake was resumed on the first postoperative day, and the length of her hospital stay was three days. Pathological examination confirmed a cortical adenoma of the adrenal gland. No surgical site infections or incisional hernias were noted during outpatient follow-up. Our patient has had an excellent cosmetic result on postoperative follow-up.

\section{Discussion}

A conventional MPLA using three or four ports is the gold standard operative treatment for benign adrenal diseases. The advantages of an MPLA include decreased scarring, decreased incisional pain, shorter hospitalization and faster functional recovery. Generally, the goal has been to minimize the invasiveness of this procedure by reducing the number or size of the operating ports. Since March 2009, we have been using single-port laparoscopic cholecystectomies in selected patients with benign gallbladder diseases. In addition, our team has recently performed successful advanced SPSs, such as gastrectomy, splenectomy, left adrenalectomy, Heller-Dor procedure and Nissen fundoplication [9-12].

In 2008, Castellucci et al. [13] reported the first SPLA in a 63 -year-old female patient with a $4.5 \mathrm{~cm}$ left adrenal incidentaloma. They used a three-port technique, introduced through a $2.5 \mathrm{~cm}$ supra-umbilical incision and successfully removed a pheochromocytoma. However, SPLA is still limited by the surgical team's adrenal and laparoscopic experience [14-17]. At our institution, SPLA was introduced after more than 80 adrenalectomies were conducted using a laparoscopic approach. This report documents our first patient to undergo a SPLA through her umbilicus for a right-sided adrenal tumor. The most important technical challenge for right-sided SPLA is 

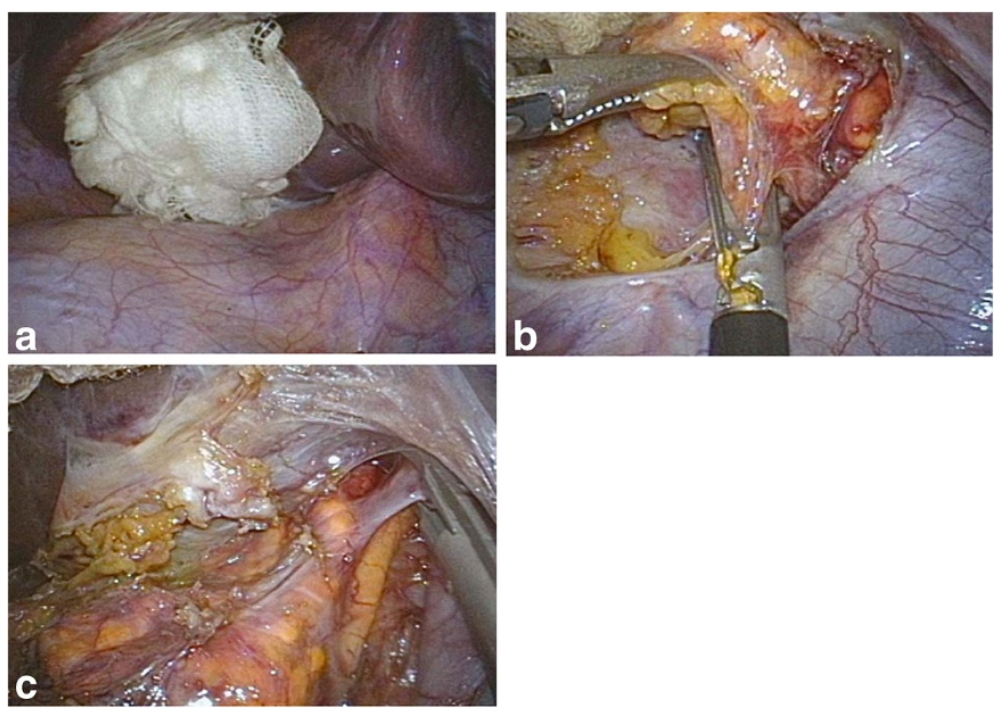

Figure 3 Intraoperative findings. (a) Good visualization of the operative field using a MiniLap. (b) Adrenal dissection using a tissue sealing device. (c) Clipping of the right central adrenal vein.

providing a good operative field surrounding the right adrenal gland. However, elevation of the right liver lobe using a MiniLap provided good visualization of the operative field, which reproduced a similar MPLA. The assistance of the needlescopic instrument does not compromise the cosmetic outcome; this outcome is still considered to be one of the main advantages of SPLA over MPLA.

In our experience, with 27 conventional MPLAs for patients with right-sided aldosterone-producing adenomas, the median operating time was 90 minutes (range, 60 to 155 minutes) and the median blood loss was $5 \mathrm{~mL}$ (range, 1 to $57 \mathrm{~mL}$ ). No differences were noted in operative outcomes between SPLA and MPLA. In the future, we believe that this approach for treating a right-sided adrenal tumor might be one of the next frontiers of laparoscopic surgery because of the benefits gained from using SPS, such as higher cosmesis satisfaction in patients and the lack of differences in operative outcomes between SPLA and MPLA.

\section{Conclusions}

Based on our experience with this case, we believe that SPLA is a safe and feasible procedure for patients with a right-sided small adrenal tumor when performed by a surgeon experienced in laparoscopic and adrenal surgery. However, more surgical experience using this technique is required to confirm our initial impressions.

\section{Abbreviations}

MPLA: Multiport laparoscopic adrenalectomy; SPLA: Single-port laparoscopic adrenalectomy; SPS: Single-port surgery.

\section{Competing interests}

The authors declare that they have no competing interests.

\section{Acknowledgments}

The authors would like to thank Dr Yuki Tomisawa for helpful discussions and Yuka Nyuzuki for copy-editing.

\section{Consent}

Written informed consent was obtained from the patient for publication of this case report and any accompanying images. A copy of the written consent is available for review by the Editor-in Chief of this journal.

\section{Authors' contributions}

AS drafted the first manuscript. AS, SB, TO, AU and MM cared for the patient. GW helped to draft the manuscript. All authors read and approved the final manuscript.

Received: 20 September 2011 Accepted: 18 July 2012

Published: 18 July 2012

\section{References}

1. Gagner M, Lacroix A, Bolté E: Laparoscopic adrenalectomy in Cushing's syndrome and pheochromocytoma. N Engl J Med 1992, 327:1033.

2. Smith CD, Weber CJ, Amerson JR: Laparoscopic adrenalectomy: new gold standard. World J Surg 1999, 23:389-396.

3. Prager G, Heintz-Peer G, Passler C, Kaczirek K, Scheuba C, Niederle B: Applicability of laparoscopic adrenalectomy in a prospective study in 150 consecutive patients. Arch Surg 2004, 139:46-49.

4. Poulose BK, Holzman MD, Lao OB, Grogan EL, Goldstein RE: Laparoscopic adrenalectomy: 100 resections with clinical long-term follow-up. Surg Endosc 2005, 19:379-385.

5. Walz MK, Alesina PF, Wenger FA, Deligiannis A, Szuczlik E, Petersenn S, Ommer A, Groeben H, Peitgen K, Janssen OE, Philipp T, Neumann HP, Schmid KW, Mann K: Posterior retroperitoneoscopic adrenalectomyresults of 560 procedures in 520 patients. Surgery 2006, 140:943-948.

6. Lee PC, Lo C, Lai PS, Chang JJ, Huang SJ, Lin MT, Lee PH: Randomized clinical trial of single-incision laparoscopic cholecystectomy versus minilaparoscopic cholecystectomy. Br J Surg 2010, 97:1007-1012.

7. Tsimoyiannis EC, Tsimogiannis KE, Pappas-Gogos G, Farantos C, Benetatos N, Mavridou $P$, Manataki A: Different pain scores in single transumbilical incision laparoscopic cholecystectomy versus classic laparoscopic cholecystectomy: a randomized controlled trial. Surg Endosc 2010, 24:1842-1848. 
8. Ma J, Cassera MA, Spaun GO, Hammill CW, Hansen PD, Aliabadi-Wahle S: Randomized controlled trial comparing single-port laparoscopic cholecystectomy and four-port laparoscopic cholecystectomy. Ann Surg 2011, 254:22-27.

9. Sasaki A, Koeda K, Obuchi T, Nakajima J, Nishizuka S, Terashima M, Wakabayashi G: Tailored laparoscopic resection for suspected gastric gastrointestinal stromal tumors. Surgery 2009, 147:516-520.

10. Sasaki A, Koeda K, Nakajima J, Obuchi T, Baba S, Wakabayashi G: Singleincison laparoscopic gastric resection for submucosal tumors: report of three cases. Surg Today 2011, 41:133-136.

11. Oyama K, Sasaki A, Chiba T, Nitta H, Otsuka K, Wakabayashi G: Singleincision laparoscopic splenectomy for idiopathic thrombocytopenic purpura: report of a case. Surg Today 2011, 41:1091-1094.

12. Shimabuku M, Sasaki A, Higa M, Kakazu M, Asato M, Shiroma H: Singleincision laparoscopic adrenalectomy for primary aldosteronism: report of a case. Surg Today 2011, 41:1306-1309.

13. Kobayashi M, Mizuno M, Sasaki A, Arisue A, Akiyama S, Wakabayashi G: Single-port laparoscopic Heller myotomy and Dor fundoplication: initial experience with a new approach for the treatment of pediatric achalasia. J Pediatr Surg 2011, 46:2200-2203.

14. Castellucci SA, Curcillo PG, Ginsberg PC, Saba SC, Jaffe JS, Harmon JD: Single port access adrenalectomy. J Endourol 2008, 22:1573-1576.

15. Walz MK, Groeben H, Alesina PF: Single-access retroperitoneoscopic adrenalectomy (SARA) versus conventional retroperitoneoscopic adrenalectomy (CORA): a case-control study. World J Surg 2010, 34:13861390.

16. Chung AD, Huang CY, Wang SM, Tai HC, Tsai YC, Chueh SC: Laparoendoscopic single-site (LESS) retroperitoneal adrenalectomy using a homemade single-access platform and standard laparoscopic instruments. Surg Endosc 2011, 25:1251-1256.

17. Rane A, Cindolo L, Schips L, De Sio M, Autorino R: Laparoendoscopic single site (LESS) adrenalectomy: technique and outcomes. World J Urol 2011, [Epub ahead of print].

\section{doi:10.1186/1752-1947-6-208}

Cite this article as: Sasaki et al: Single-port laparoscopic adrenalectomy for a right-sided aldosterone-producing adenoma: a case report. Journal of Medical Case Reports 2012 6:208.

\section{Submit your next manuscript to BioMed Central and take full advantage of:}

- Convenient online submission

- Thorough peer review

- No space constraints or color figure charges

- Immediate publication on acceptance

- Inclusion in PubMed, CAS, Scopus and Google Scholar

- Research which is freely available for redistribution 